EVS28

KINTEX, Korea, May 3-6, 2015

\title{
Norwegian electric car user experiences 2014
}

\author{
Petter Haugneland ${ }^{1}$, Espen Hauge ${ }^{2}$ \\ I(corresponding author) Norwegian Electric Vehicle Association (petter@elbil.no).
}

\begin{abstract}
The Norwegian Electric Vehicle Association has for the three last years conducted an EV user survey among their members and other EV users and owners in Norway. The survey shows that nearly $100 \%$ of the Norwegian EV owners are satisfied with their electric car. And for every satisfied EV owner, there will be three more. The main conclusion from the Norwegian experience to start a sustainable market for EVs, is that the purchase price for an EV must be competitive with a similar car model. In Norway, this is achieved with a combination of high taxes on cars with high emissions and zero tax for zero emissions cars. Because of the policy, Norway has the highest number of electric cars per capita in the world. By January 2015, Norway reached 40,000 electric cars in a country of 5 million inhabitants. In Norway, about $12 \%$ of all new cars sold in 2014 were electric. Over $1.5 \%$ of 2.5 million cars in Norway are now electric. Norway is a frontrunner in the $\mathrm{EV}$ market.
\end{abstract}

Keywords: EV (battery electric vehicle), Charging, Fast charge, Incentive, Infrastructure, Policy

\section{Introduction}

Norway has the highest number of electric cars per capita in the world. By January 2015, Norway reached 40,000 electric cars in a country of 5 million inhabitants. In Norway, about $12 \%$ of all new cars sold in 2014 were electric.

By September 2014, over $35 \%$ of the total EVs sold in Western Europe was in Norway [1]. Unlike many other countries, the vast majority of EVs sold in Norway is fully electric, not plug-in hybrids. The EV market in Norway is also dominated by private owners, not company fleet cars.

\subsection{About the survey}

The last three years, The Norwegian Electric Vehicle Association have been conducting an EV user survey among their members and other EV users and owners in Norway. In the survey, we ask electric car owners about background details, how they drive and charge their car, and their opinions on the EV market and Norwegian EV policy. The experiences from the Norwegian EV owners provide valuable input to decisions makers. In this paper, we will analyze the data from the 2014 survey and compare it to previous surveys in 2013 [2] and 2012.

In the most recent 2014 survey, we have 3,405 respondents who own and use an electric car. When we conducted the survey during the two first weeks of June 2014, they corresponded to $12 \%$ of all the electric cars in Norway. In the 2013 survey, a total of 1,858 persons submitted the online survey form and the 2012 survey had 459 respondents.

\section{The typical Norwegian EV user}

The typical Norwegian EV user is a family father with high education and high income. He recently 
bought a Nissan LEAF as one of two cars in the household. He lives in or within one of the bigger cities in Norway.

In the 2014 survey, there are many new electric car owners. 2,015 respondents (59\%) have been driving an electric car for less than one year (fig 1). This is due to the explosive growth in new electric cars in Norway. In the first half of 2014, the sales reached 10,000, already more than the total sales of EVs in Norway in 2013. $81 \%$ of the EVs in Norway are privately owned [3]. Only $5 \%$ of the respondents in the 2014 survey have an $\mathrm{EV}$ as a company car.

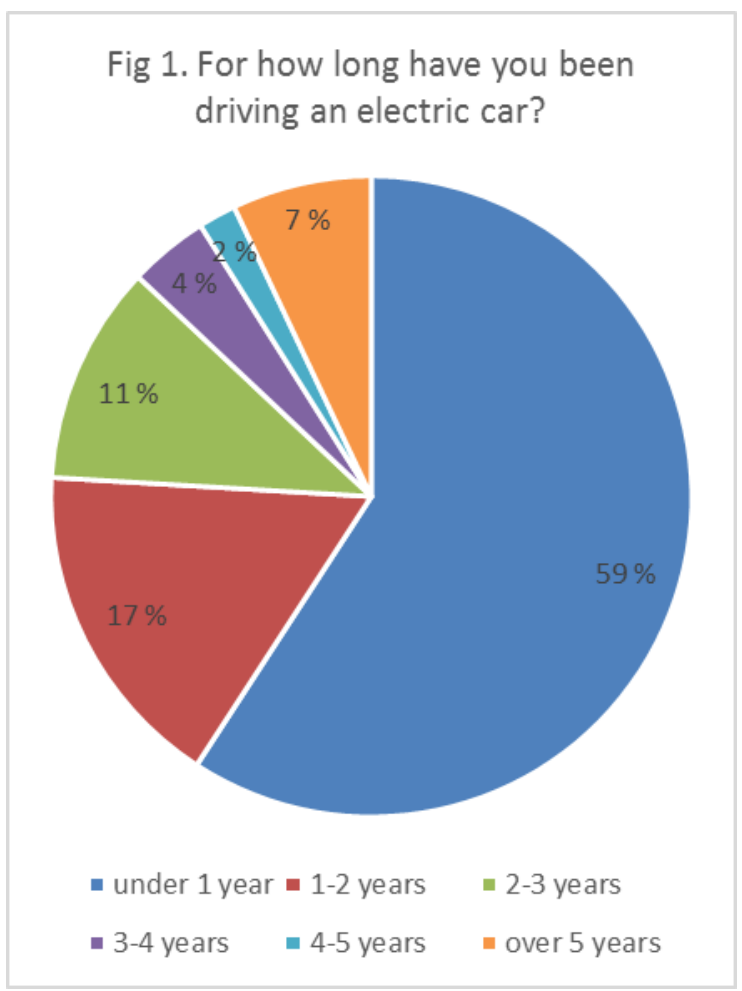

Out of the 3,405 respondents, 1,362 owns a Nissan LEAF (38\%) and 980 owns a Tesla Model S (27\%). The rest is more or less evenly distributed between the other EV models like Mitsubishi i-MiEV (8\%), Peugeot iOn (3\%), Citroën C-ZERO ( $3 \%$ ), VW e-up (6\%), BMW i3 (4\%) and Think City (3\%) (fig 2). The distribution of the electric car ownership in the survey corresponds well with the total market share [3], although Tesla Model S owners are overrepresented in the survey.

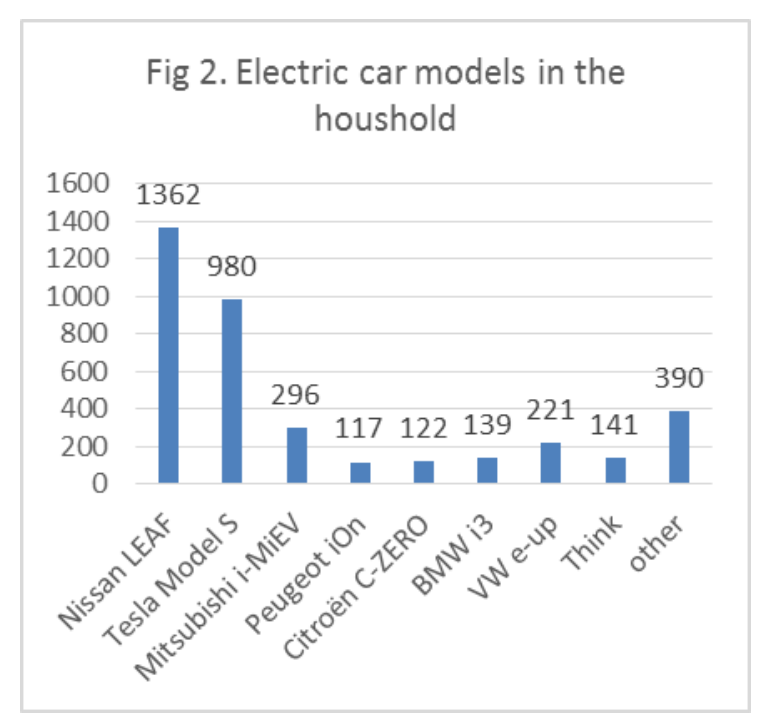

A big majority of the EV drivers has two or more cars in their household. Maybe surprisingly, one out of four $(25 \%)$ make due with only the one electric car in the household (fig 3). This is an increase from about $15 \%$ in the 2013 survey. The Tesla Model S owners have the largest share with only one electric car in their household in the 2014 survey. About $7 \%$ of the respondents have two or more electric cars in their household.

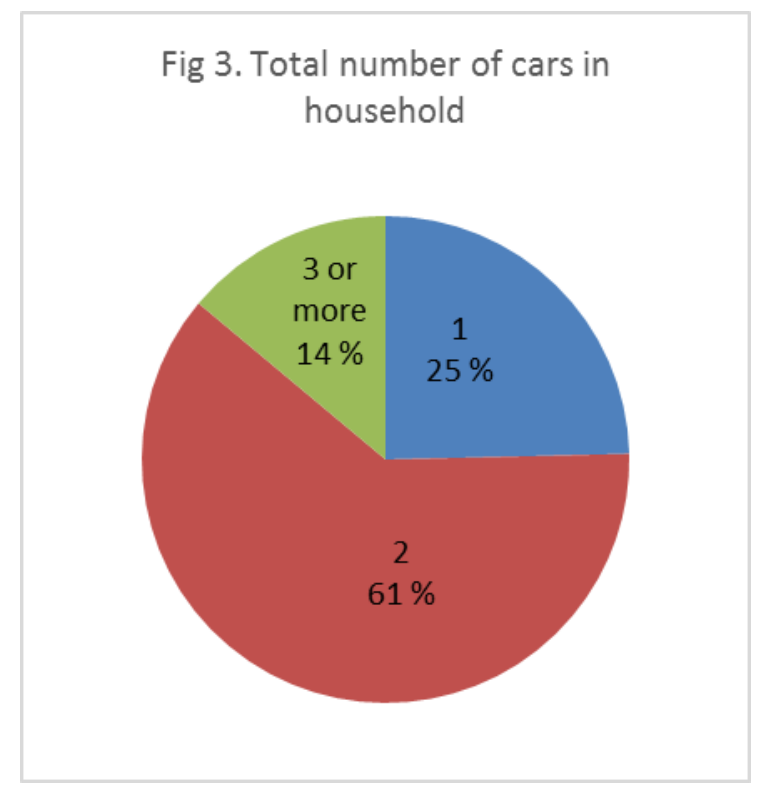

The Norwegian EV driver has high education (fig 4) and high income. As many as $76 \%$ have higher education at university- or college-level. In the total Norwegian population over 16 years, the share is $29 \%$ with higher education [4]. 


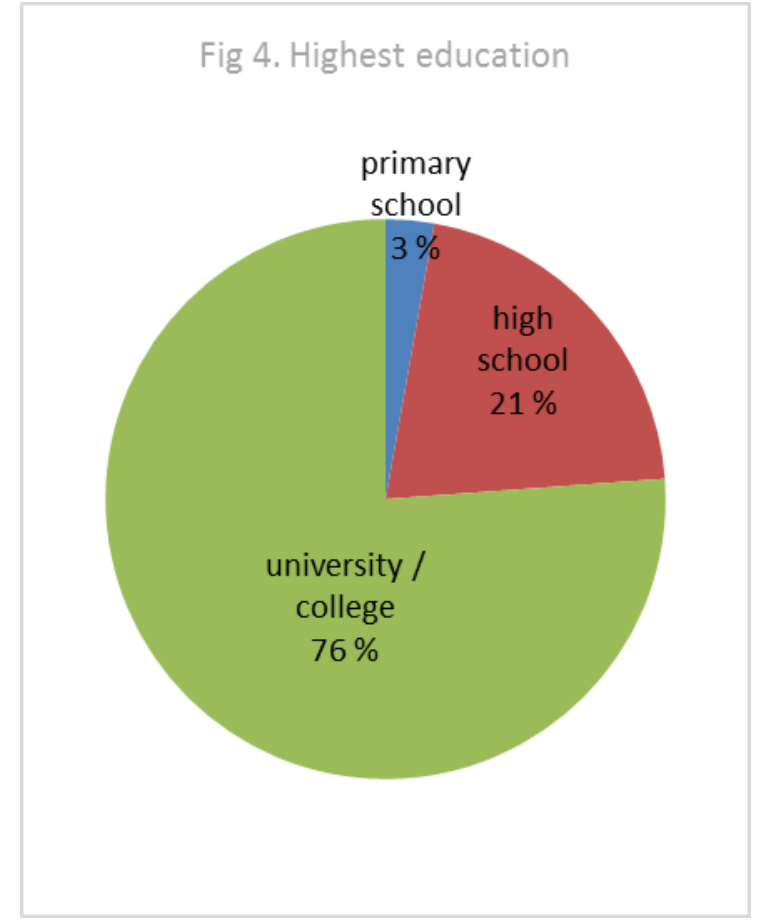

\subsection{Electric car for everyday use}

The electric car replaces in large part the use of traditional cars, even if most of the EV owners have a second car for longer trips.

The EV-owner use their electric car on a daily basis commuting to work, to shops and after work activities by most of the respondents (fig 5). In the 2014 survey, about a third (34\%) of the respondents use their EV for vacation trips. This is a big increase from the 2013 survey where only $217(12 \%)$ of the 1,859 respondents used their EV for vacation trips. This is probably due to the new Tesla Model S with longer range and a bigger network of fast charging stations in Norway. About half of the respondents who use their EV for vacations own a Tesla Model S.

The average yearly driving distance is also increasing for EVs. In the latest survey only 285 respondents $(8 \%)$ have insured their $\mathrm{EV}$ for less than $8.000 \mathrm{~km}$ each year. The largest group of 824 respondents have $(24 \%)$ have insured their $\mathrm{EV}$ for $12-16.000 \mathrm{~km}$. This is close to the average yearly driving distance for all cars in Norway.

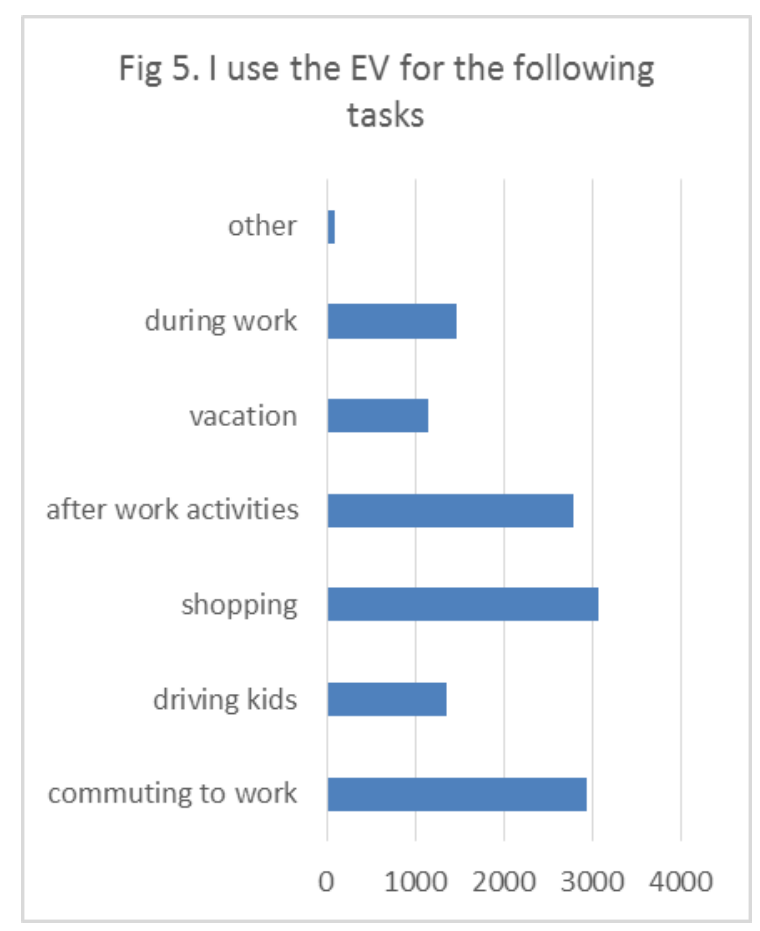

On the question «How did you get to work before you bought an EV?», 2,659 (78\%) respondents answered «traditional car» (fig 6). The reminding $10 \%$ traveled to work with public transport and 6 $\%$ walked or used bicycle.

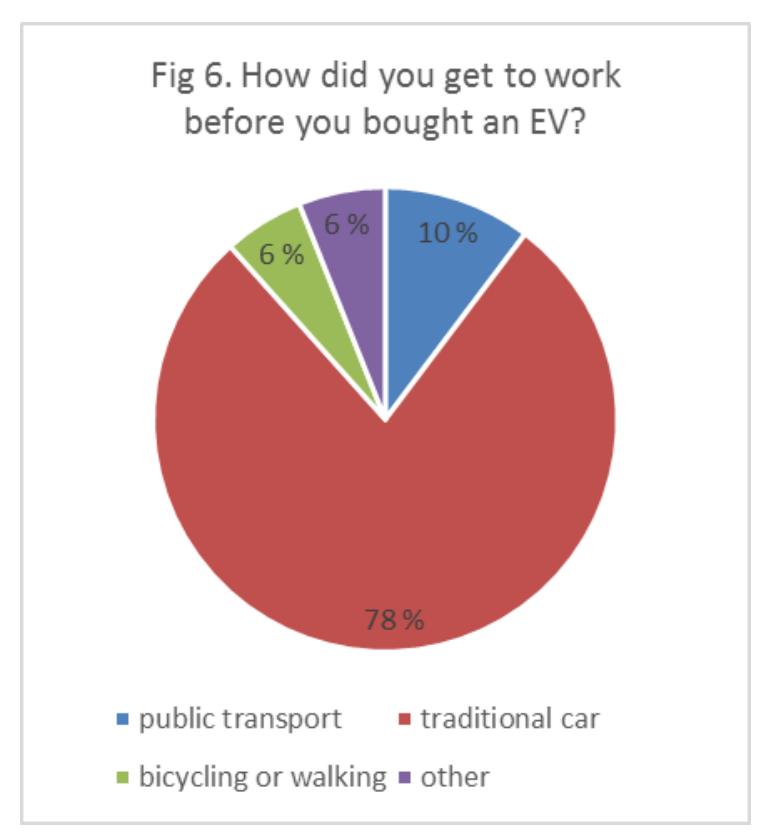

A similar survey from Instiute of Transport Economics confirms this result. $80 \%$ of the respondents drove a conventional car to work before they bought an EV [5]. 
Another similar statement is «My EV has replaced the use of a traditional car...», $48 \%$ answers «totally» and $45 \%$ to a «large degree». This shows that the EV in most cases replaces the use of traditional cars with emissions, not other environmental modes of transport. This shows us yet again that the EV for the most part replaces the use of traditional cars. In fact, our experience is that many EV owners buy their EV as the second car in the family, but it rapidly becomes the first car because it is cheaper and more fun to drive. The second car is only used for occasional longer trips.

\subsection{Very satisfied EV owners}

As previous years, the Norwegian EV owners are still very satisfied with their electric car (fig 7). In the 2014 survey, 3,075 (91\%) answers «very satisfied» to the question «How satisfied are you as an EV owner?». 309 (9\%) respondents answer «satisfied» and only 15 respondents are unsatisfied. In the 2013 survey, the same $91 \%$ answer that they are very satisfied. The reminding $9 \%$ are reasonably satisfied. Only 7 respondents of the total 1,858 were less satisfied or unsatisfied.

Fig 7. How satisfied are you as an EV owner?

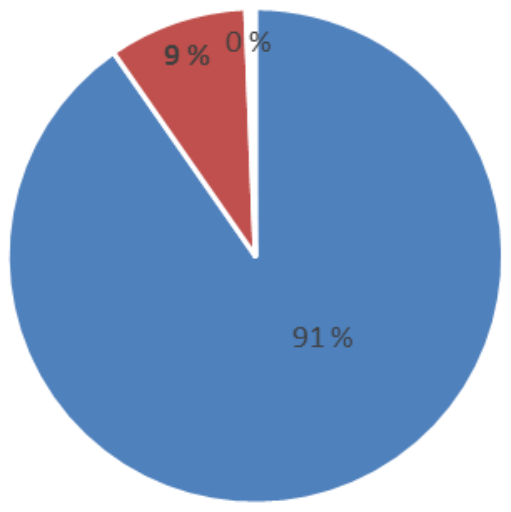

- very satisfied - satisfied

- unsatisfied - very unsatisfied

- don't know

On the question «If I should buy a car tomorrow, it would be», 2,532 (74\%) answered «electric car» in the 2014 survey (fig 8). 300 (9\%) answered «plug-in hybrid» and only $203(6 \%)$ answered «traditional car». In the 2012 and 2013 survey we asked if the next car also will be electric. $64 \%$ answered yes, an increase from 59 $\%$ in the 2012 survey. Only $5 \%$ answered no to buying an electric car again in both the 2012 and 2013 survey [2].

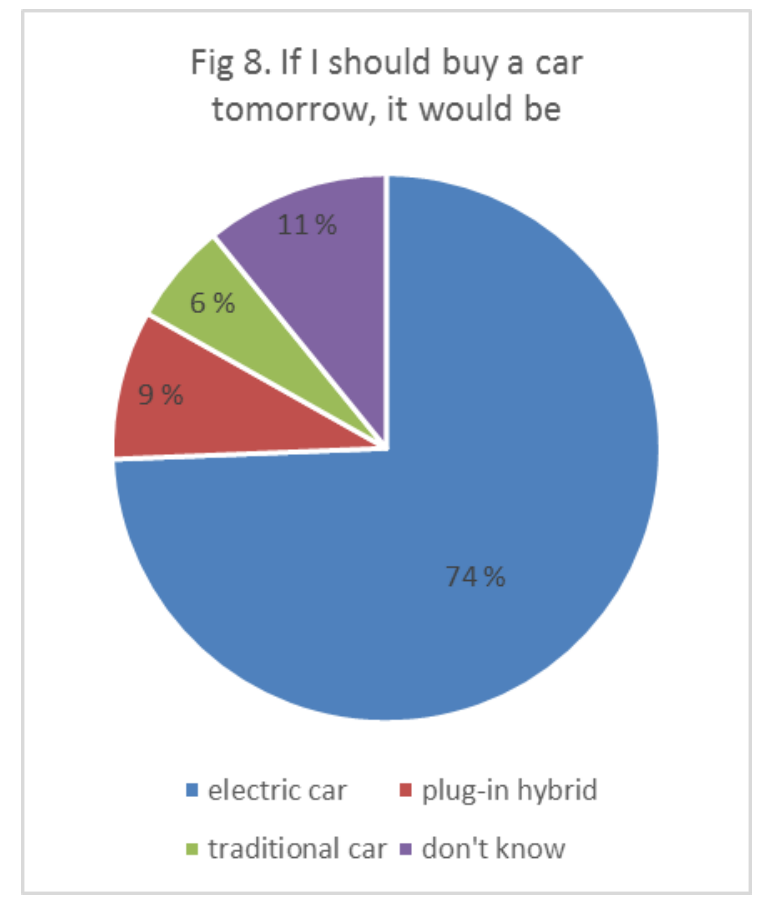

For the total Norwegian population the picture is opposite from what current EV owners consider for their next car. Only $21 \%$ of Norwegians considers an EV, but $35 \%$ considers a plug-in hybrid [9].

Satisfied EV owners are ambassadors for the shift to electric cars. We have asked them how many they think they have inspired to buy an EV amongst their friends and relatives (fig 9). A majority have recruited two or more new EV owners. In average, one satisfied electric car owner will inspire three more people to buy an EV. Considering that most of them only have owned their EV for less than one year, the future looks bright for the Norwegian EV market. 


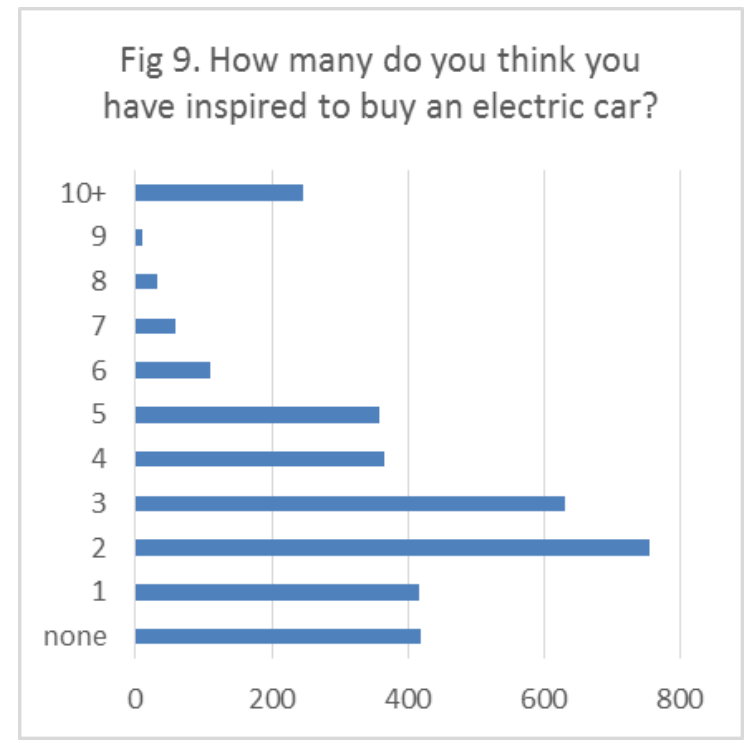

The current EV owners are also very important to dissiminate facts and clarify myths about electric cars. The knowlegde about electric cars are still relatively low in the general public. 2,244 respondents $(66 \%)$ agree that they often have to clarify myths about electric cars to people they meet.

Finally, the EV owners are also more conscious about their energy use after they bought their EV. 2.318 respondents $(68 \%)$ agree that they are more energy conscious after they became an EV owner. For example, 737 of them $(22 \%)$ consider installing solar panels on their own house. This positive side effect of the EV policy is not to be ignored [8].

\subsection{Economy is most important}

The most important reason for choosing an EV over a traditional car is economy (fig 10). 1,653 (48\%) respondents states that economy is the most important reason for their choice of an EV. For $904(27 \%)$ it is saving the environment and for $395(12 \%)$ it is saving time.

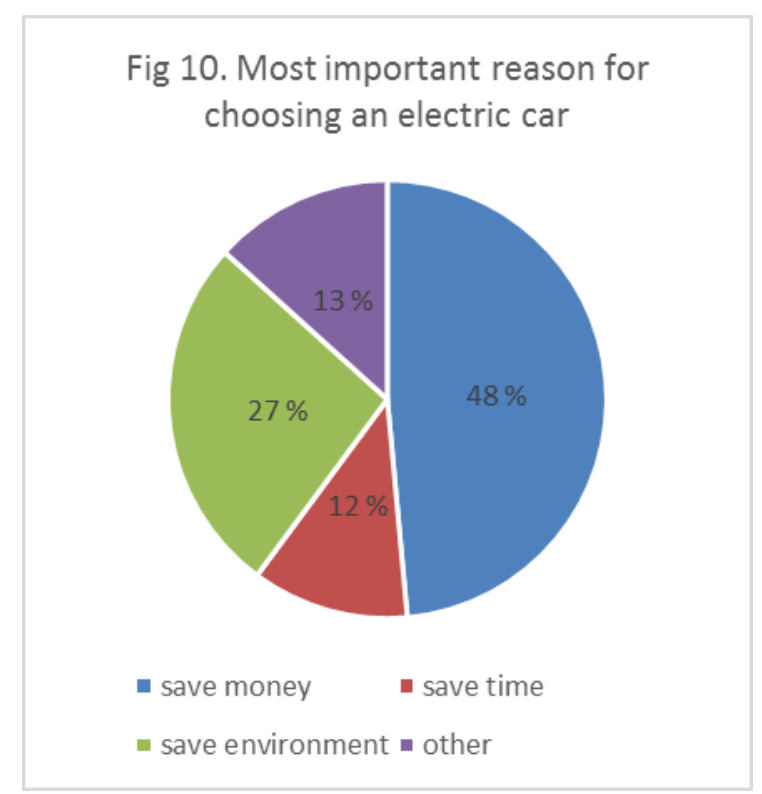

Even if economy is the single most important reason for choosing an $\mathrm{EV}$, the effect is still the same. Regardless of the motivation, they still drive without any emissions of $\mathrm{CO}_{2}$ or local pollutions as NOx. In Norway, the electricity is close to $100 \%$ renewable hydropower. This makes the electric car especially environmental friendly compared to a traditional car. The Norwegian case shows that we need strong economic incentives to encourage people to choose an electric car. Even if you consider yourself an environmentalist, there is a limit for how much more you are willing to pay to drive a zero emission car.

The Norwegian EV policy is a broad package of incentives that makes the $\mathrm{EV}$ competitive compared to traditional cars. The incentives include [3]:

- $\quad$ zero VAT on purchase (normally 25\%)

- no import tax (very high for big cars with high emissions)

- low annual road fee

- free toll roads

- free national ferries

- free municipal parking

- free charging at most normal charging stations

- $\quad$ access to drive in bus lanes

When we ask the respondents in the 2014 survey to rank all the incentives, the purchase incentives zero VAT and import tax comes at top (fig 11). This makes the electric car competitive compared to a similar traditional car. But it is the zero VAT that is most effective in lowering the purchase 
price. Since the import tax is partly based one the $\mathrm{CO}_{2}$ emissions, most EVs would have zero or very low import tax even without the exemption for zero emission cars. Most people are probably not aware of this difference between the VAT and import tax for electric cars.

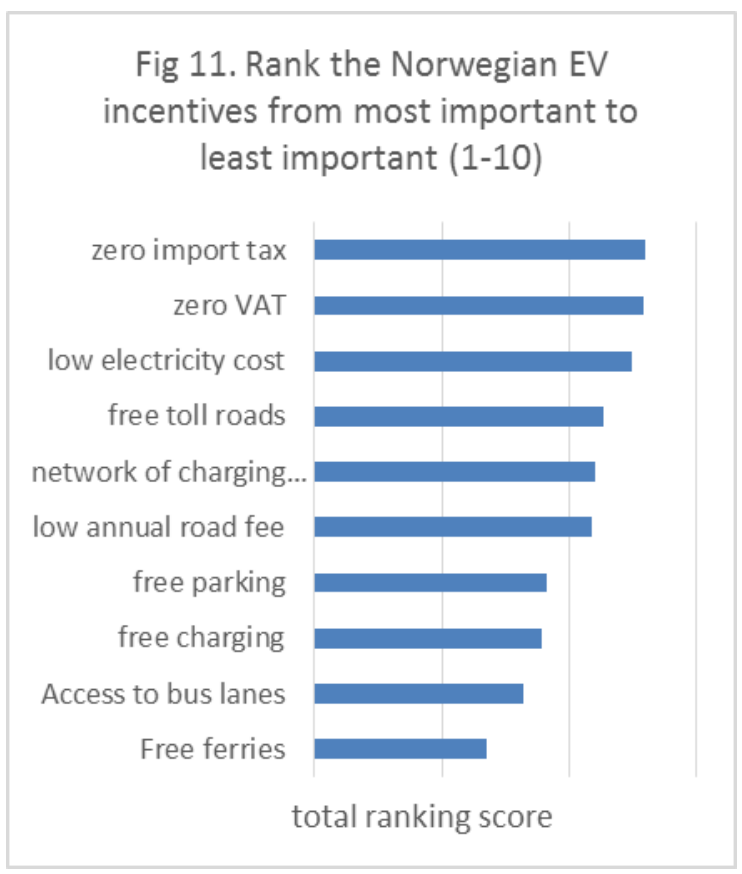

\subsection{Competitive purchase price}

The difference in purchase price in Norway, Sweden and Denmark can explain why the EV sales are much higher in Norway. A VW e-Golf or e-Up will cost less or the same as a petrol version of the model in Norway. In Sweden, the electric versions cost over 10,000 Euros more than the petrol version. This is after the price reduction of about 4,300 Euros for cars with low emissions in Sweden. In Denmark, the e-Golf is priced similar to the petrol version, but the smaller e-Up is like in Sweden 10.000 Euros more expensive than the Up. (fig 12).

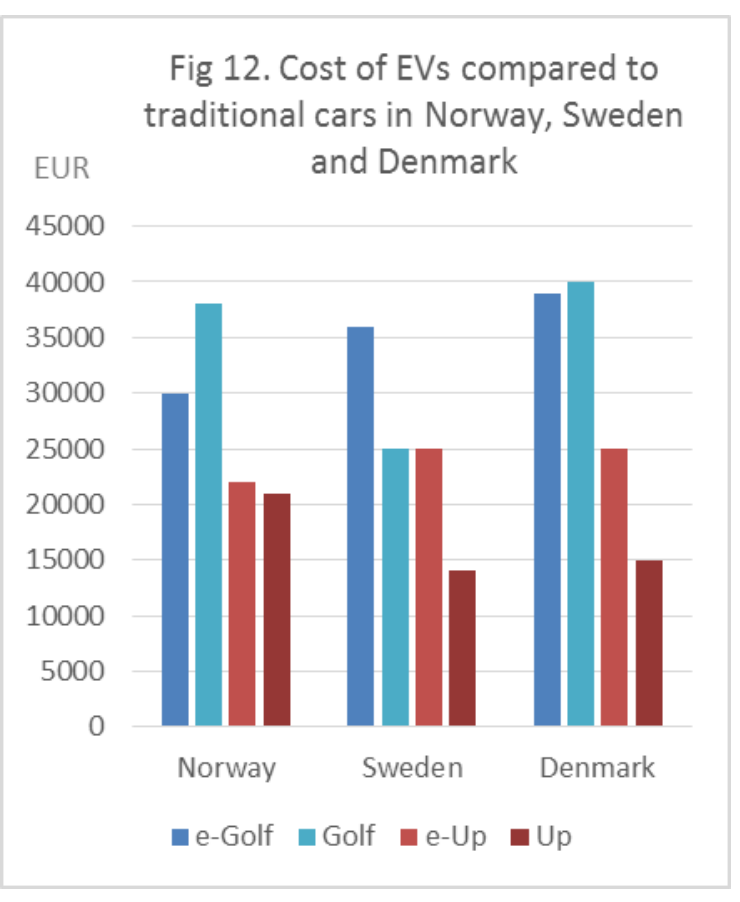

The main conclusion from the Norwegian experience, for other countries to learn from, is that the purchase price for an EV must be competitive with a similar car model. In Norway, this is achieved with a combination of high taxes on cars with high emissions and zero tax for zero emissions cars. The incentives in use, as free toll roads and access to the bus lanes, are to compensate for the disadvantage of being first movers on electric cars. The Norwegian case shows that people need strong incentives to move to new and unknown technology.

\subsection{Charging infrastructure}

The latest few years, the establishment of a national charging network is lagging behind the impressive sales figures in Norway. With a doubling of EV sales every year since 2011, the number of charging stations have not increased equivalent the latest few years. After a big increase in charging points in 2009 from under 500 to over 2,500 , the total number of charging points was 6,186 in January 2015. At the same time, the number of electric cars have increased from 2,749 in 2009 to 41,051 by January 2015. This is also over a tenfold increase since 2009 (Fig 13). Today there are about 7 electric cars per public charging point in Norway. In many places this does not cover the need for charging, especially during winter when the range is shorter than normal. 


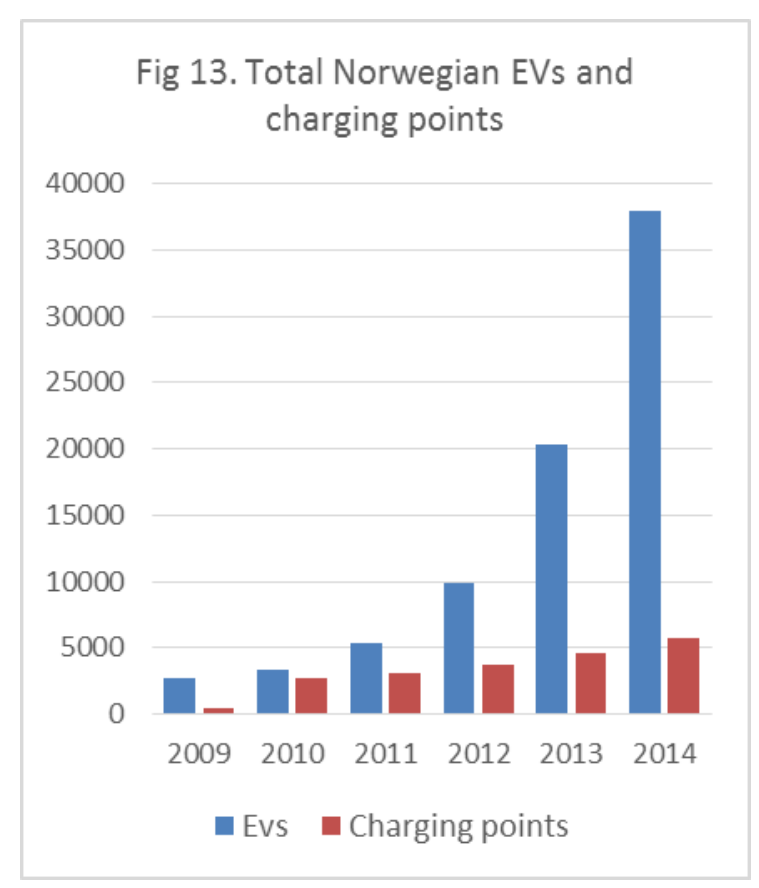

Unlike for instance Denmark, Norway has so far no national grid of fast charging stations. In January 2015 there are 220 fast charging stations in Norway and 68 more planned in the near future. 159 charging points with CHAdeMO, 132 Tesla, 96 Combo and 44 AC Type 2, in addition to $196 \mathrm{AC}$ Type 2 semi fast $22 \mathrm{~kW}$ chargers [6].

This tells us that a national grid of fast charging stations is not a prerequisite for the booming EV sales. The Norwegian EV drivers charge their electric car at home or at work (fig 14).

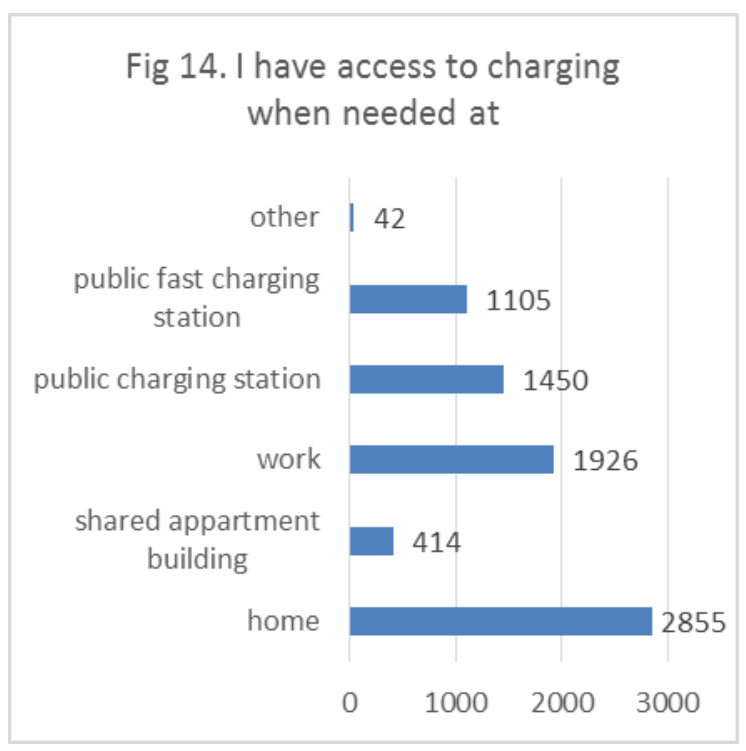

Almost all of the respondents in the 2014 survey have access to charging where they live. In addition, about half of them also have access to charging at work. This should cover most of their need for charging in their everyday driving. About a third of the respondents also have access to public charging stations.

When we ask how often they used public charging stations the previous month, the majority said less than weekly or never (fig 15). This was in May 2014 when the temperature is optimal and the need for charging is less than during the winter. The results would probably be more frequent public charging if we had asked the same question during winter.

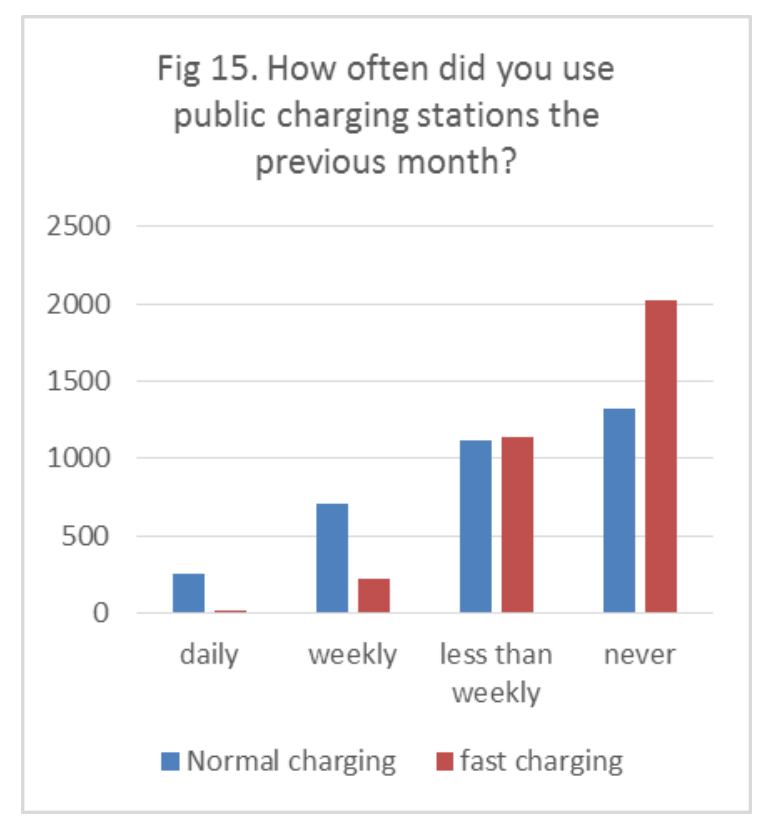

Even if the need for public charging stations seems low, the respondents still value network of charging stations quite high, at number five (fig 11). One explanation could be that the frequency of charging would be higher if there were more public charging stations available. In the EV capital Oslo, for instance, the public charging stations are very popular and it is increasingly more difficult to find one available.

The range of the electric cars are a very hot topic in Norway. During the cold Scandinavian winter the range in practice can in worst case be halved compared to ideal summer temperatures [3].

It seems that the EV drivers love their electric car so much that they want to use it also for longer trips. This means that there is a need for more fast charging stations and more battery capacity in new electric cars. 
We have asked the EV users how much they would be willing to pay for a doubling of the battery capacity in their EV. For Nissan Leaf owners, the average willingness to pay for doubling the battery capacity and range is about 4,500 Euros. Only 84 out of the 1240 Nissan Leaf owners say they don't need double range and 121 persons don't know how much they are willing to pay.

For the Tesla Model S owners the picture is quite different. Tesla Model $\mathrm{S}$ has a much bigger battery capacity and longer range than all other electric cars. The average willingness to pay for doubling the capacity in a Tesla Model S is only about 6,650 Euros. 292 of the 830 Tesla Model S owners state that they don't need to double the range and 58 persons don't know how much they would pay.

For the fast charging network it seems like it is most important for potential EV buyers and as a security measure to ease the range anxiety of current EV owners. If you consider buying an electric car and you are uncertain if it can fill your transportation needs, a functional fast charging network would be helpful to convince you. However, this is not sufficient if you compare the Norwegian and Danish case.

Most current EV owners have realized that they don't need a fast charger for their everyday use and the willingness to pay extra for the fast charging service is low (fig 16). In Norway, the renewable hydropower electricity is relatively cheap at about 10 Eurocent per $\mathrm{kWh}$ including grid rent and tax [7]. As much as three out of four EV owners are not willing to pay more than maximum 30 Eurocent per $\mathrm{kWh}$ for faster charging services. The majority $(36 \%)$ are willing to pay twice as much (20 Eurocent per $\mathrm{kWh})$ as they pay for electricity at home.

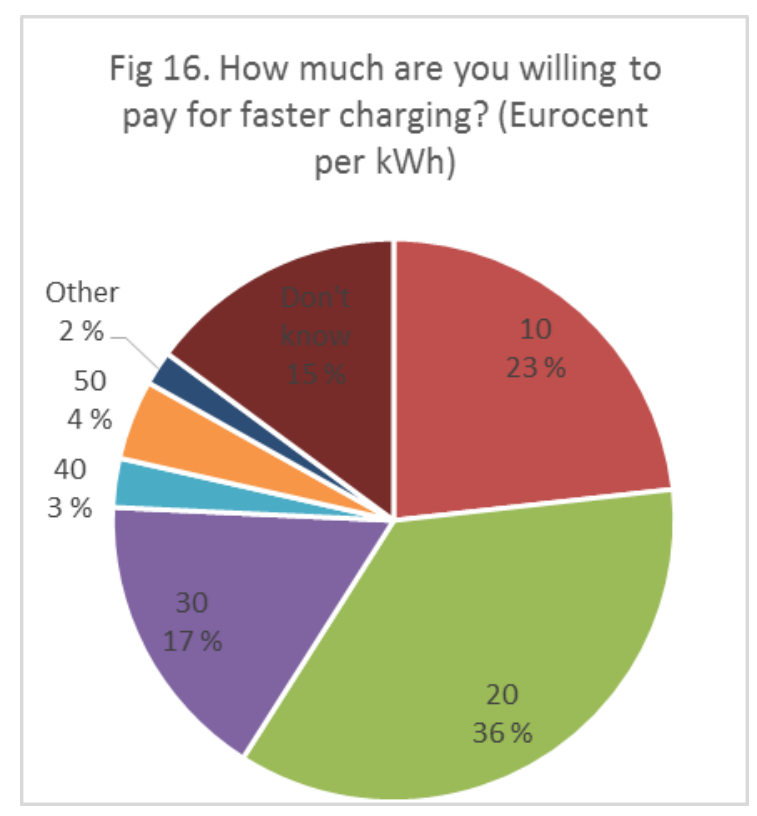

It is difficult to find a sustainable business model with the low willingness to pay in the current Norwegian market. In this perspective, the Tesla business model with free fast charging included in the purchase price might seem more attractive.

\section{Conclusions}

The Norwegian EV success story is an interesting test case for decision makers in governments and industry. No other country in the world has a higher share of electric cars. In Norway, about 12 $\%$ of all new cars in 2014 were electric. Over 1.5 $\%$ of 2.5 million cars in Norway are electric. Norway is a frontrunner in the EV market.

Our survey among 3,405 Norwegian EV owners shows that EVs, in most cases, replace the use of traditional cars with emissions, not other environmental modes of transport. They need strong incentives to move to new and unknown technology to reduce emissions and traffic noise.

The main conclusion from the Norwegian experience, for other countries to learn from, is that the purchase price for an EV must be competitive with a similar car model. In Norway, this is achieved with a combination of high taxes on cars with high emissions and zero tax for zero emissions cars.

Nearly $100 \%$ of the Norwegian EV owners are satisfied with their electric car. Our survey suggests that for every happy EV owner there will be three more. The future of the Norwegian EV market looks bright. However, other countries 
must follow to support a sustainable global EV market.

\section{References}

[1] InsideEVs. Registrations In Western Europe Down In August. Accessed 13.10.2014. http://insideevs.com/eagleaid-evregistrations-in-western-europe-down-inaugust/

[2] P.Haugneland and H.Kvisle. Norwegian Electric car user experiences. EVS27. 2013 http://www.elbil.no/elbilforeningen/dokume ntarkiv/finish/9-diverse/43-norwegianelectric-car-user-experiences-evs27-paper

[3] EV Norway. What does the Norwegian EV market look like today? Accessed 30.01.2015. http://evnorway.no/\#/now

[4] Population's level of education. Statistics Norway. Accessed 13.10.2014.

http://www.ssb.no/en/utdanning/statistikker/ $\underline{\text { utniv }}$

[5] E.Figenbaum, M.Kolbenstveid and B.Elvebakk. Electric Vehicles environmental, economic and practical aspects. As seen by current and potential users. Instiute of Transport Economics Report 1329/2014.

https://www.toi.no/publikasjoner/elbilermiljomessige-okonomiske-og-praktiskekjennetegn-vurdert-av-eksisterende-ogpotensielle-brukere-article32642-8.html

[6] NOBIL. The Norwegian charging station database. Accessed 30.01.2015. http://nobil.no/

[7] Statistics Norway. Electricity prices, $Q 2$ 2014. Accesses 13.10.2014.

http://ssb.no/en/energi-ogindustri/statistikker/elkraftpris

[8] Gemini. Satsing på elbil er nødvendig (in Norwegian). Accesses 30.01.2015. http://gemini.no/2014/09/satsing-pa-elbilerer-nodvendig/

[9] TNS Gallup. Klimabarometer 2014 (in Norwegian). 20.05.2014. http://www.tnsgallup.no/tns-innsikt/klimabar2014?pid=TNS-Report-ReportFile

\section{Authors}

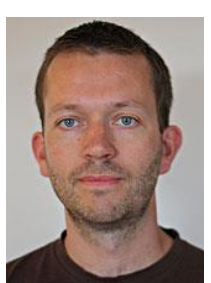

Mr. Petter Haugneland is the Communication Manager at Norwegian Electric Vehicle Association. His association represents the Norwegian EV owners and cooperates with policy makers, the electric car industry and other organizations for the successful introduction of electric vehicles.

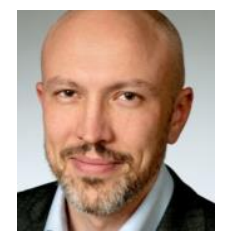

Mr. Espen Hauge is the President of Norwegian Electric Vehicle Association and Vice President in AVERE. 